\title{
Clinical Evaluation of Type I Bovine Collagen in the Treatment of Localized Gingival Recession
}

\author{
${ }^{1}$ Praveen J, ${ }^{2}$ Dwarakanath CD, ${ }^{3}$ Prashanth GV, ${ }^{4}$ Ramesh AV, ${ }^{1}$ Sidharth Shankar \\ ${ }^{1}$ Senior Lecturer, Department of Periodontics, KLE Society's Institute of Dental Sciences, Bengaluru, Karnataka, India \\ ${ }^{2}$ Professor and Head, Department of Periodontics, The Oxford Dental College and Hospital, Bengaluru, Karnataka, India \\ ${ }^{3}$ Professor and Head, Department of Periodontics, Al-Ameen Dental College and Hospital, Bijapur, Karnataka, India \\ ${ }^{4}$ Professor, Department of Periodontics, The Oxford Dental College and Hospital, Bengaluru, Karnataka, India
}

Correspondence: Praveen J, Senior Lecturer, Department of Periodontics, KLE Society's Institute of Dental Sciences, Bengaluru Karnataka, India, e-mail: jayarampraveen @yahoo.co.in

\section{ABSTRACT}

Background: Over the years, coronally advanced flap and the use of guided tissue regeneration have been among the more successful techniques in treating gingival recession. The present study compared the relative efficacies of these two techniques in treating gingival recession.

Methods: Twelve patients presenting with localized identical anterior recessions were taken up in a split mouth design for the study. One site was randomly assigned to be treated with coronally advanced flap supported by membrane while the other was treated with coronally advanced flap alone. Changes in clinical parameters, such as recession width, recession depth, surface area of the recession defect, width of keratinized tissue, gingival status, probing pocket depth and clinical attachment level were measured at baseline and at 3 and 6 months postoperatively.

Results: In the 10 patients that were followed up, both treatments resulted in a significant gain in root coverage amounting to a mean gain of $66.49 \%$ in the membrane group and $65.56 \%$ in the CAF group. The differences in root coverage and the clinical attachment level gains between the groups were not significant. However, significant gain in the width of keratinized tissue was seen in the membrane group after treatment.

Conclusion: This study suggests that coronally advanced flap procedure provides a predictable, simple and convenient technique in the treatment of localized class I gingival recession. Combining this technique with the placement of a bioabsorbable membrane does not seem to improve the results. The addition of a membrane, however, increases the width of keratinized tissue.

Keywords: Gingival recession, Guided tissue regeneration, Collagen membranes, Coronally advanced flap.

\section{INTRODUCTION}

One of the most common problems affecting the general population the causes for gingival recession could be multiple including aging, ${ }^{1}$ prior lack of alveolar bone, ${ }^{2}$ orthodontic tooth movement, ${ }^{3}$ periodontal disease, ${ }^{4}$ trauma from tooth brushing and other practices, ${ }^{5,6}$ and aberrant frenal attachments. ${ }^{7,8}$

Esthetics is an inseparable part of contemporary therapy. Root coverage procedures encompass various techniques, including lateral pedicle flaps, ${ }^{9}$ coronally advanced flaps, ${ }^{10,11}$ free gingival grafts, ${ }^{12}$ subepithelial connective tissue grafts, ${ }^{13}$ guided tissue regeneration, ${ }^{14-17}$ and more recently the use of enamel matrix proteins, ${ }^{18}$ growth factors and acellular dermal matrix. ${ }^{19}$

Guided tissue regeneration procedures offer the possibility of achieving periodontal regeneration while also increasing the width of keratinized gingiva. ${ }^{20}$ Among the many nonresorbable (PTFE, ePTFE) and resorbable (collagen, polylactic acid) membranes available currently, collagen products offer an added advantage of aiding in clot stabilization, fibroblast chemotaxis, better cell migration into the wound area, and weak antigenicity ${ }^{21}$ in addition to being resorbable.
The coronally advanced flap (CAF) is one of the first choice surgical techniques with optimum root coverage results and good color blending of the treated area.

The current study aimed to assess the efficacy of type I bovine collagen in the treatment of localized gingival recession while comparing it to a coronally advanced flap alone in a split mouth design.

\section{MATERIALS AND METHODS}

Twelve patients, 9 males and 3 females, presenting with identical Miller's class I recessions from the outpatient department of the Oxford Dental College were recruited in the study. The patients included were based on good general health, presence of paired defects presenting with Miller's class recession defects ( $\geq 2 \mathrm{~mm}$ ), with a probing depth of $<3 \mathrm{~mm}$ with no bleeding on probing. Medically compromised patients, smokers, teeth with mucogingival problems and teeth exhibiting mobility were excluded from the study.

Of the 12 patients treated, only 10 turned up for all the recall visits. The other two dropped out during the course of the study. 
One defect from each pair was randomly selected to be treated by a coronally positioned flap only or coronally positioned flap supported by a collagen membrane. The presterilized collagen membrane manufactured by Central Leather Research Institute, Chennai, India was opened only at the time of surgery.

Scaling and root planing of all the teeth were performed and 4 weeks after which re-evaluation of the sites was done. All the teeth treated in the study were maxillary canines.

Following initial therapy, study models and defect photographs were taken. Measurements were performed at baseline, 3 and 6 months. The parameters checked were width of the recession and depth of the recession, surface area of the defect, width of the keratinized gingiva present apical to the recession, plaque inde ${ }^{22}$ and gingival index. ${ }^{23}$ Clinical attachment level and probing depths were only recorded at baseline and at 6 months.

Surface area of the defect was determined by superimposing a graph sheet over the recession defect.

The percentage of root coverage was calculated according to the following formula: ${ }^{17}$

Preoperative recession area - Postoperative recession area Preoperative recession area

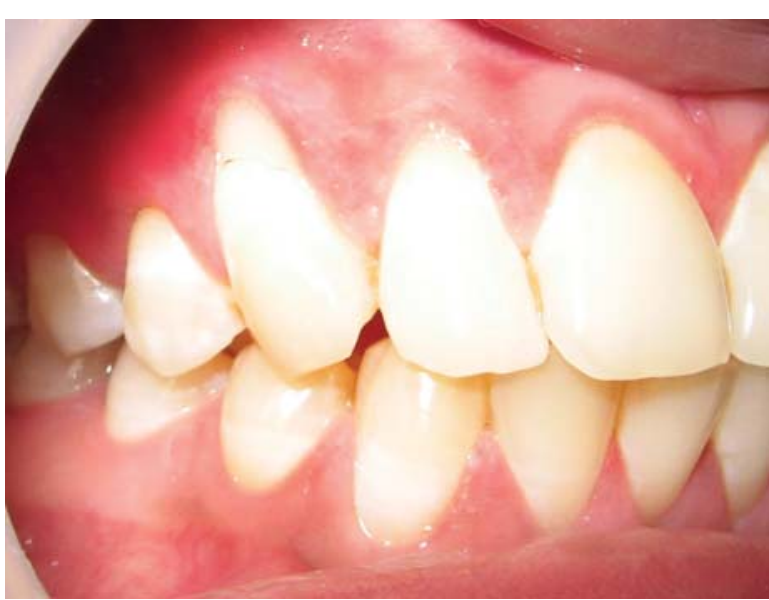

Fig. 1: Recession in relation to 13 prior to treatment with membrane

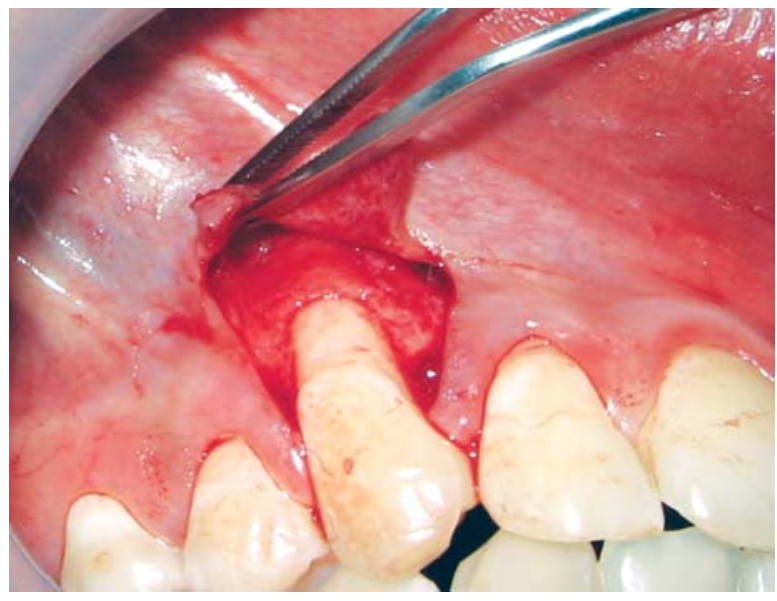

Fig. 2: Incisions given, partial thickness flap raised in relation to 13

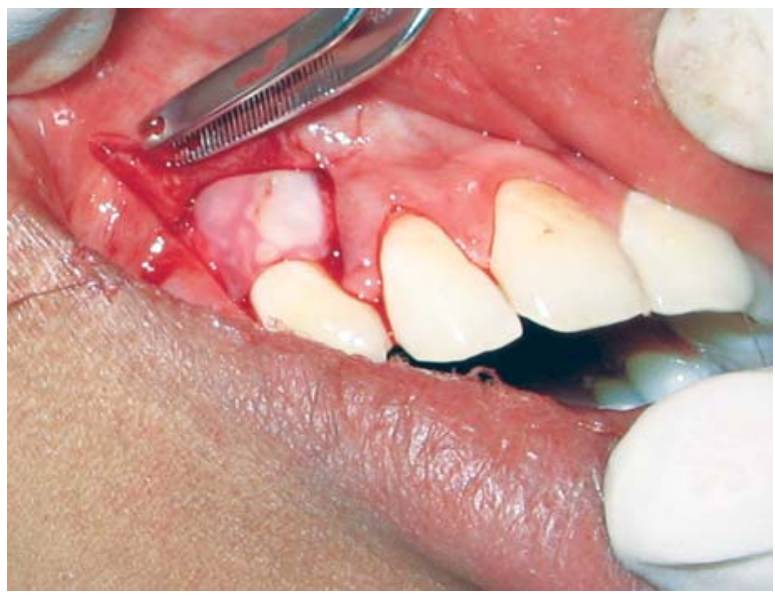

Fig. 3: Membrane placed over the defect

regimen of Amoxicillin 500 mg thrice daily for 5 days. The analgesic regimen consisted of $400 \mathrm{mg}$ of Ibuprofen given thrice daily for three days. Placed on a regimen of $0.2 \%$ chlorhexidine twice daily, all patients were instructed to abstain from brushing
A periodontal dressing was used to protect the surgical area in all cases. Antibiotic therapy was prescribed consisting of a 


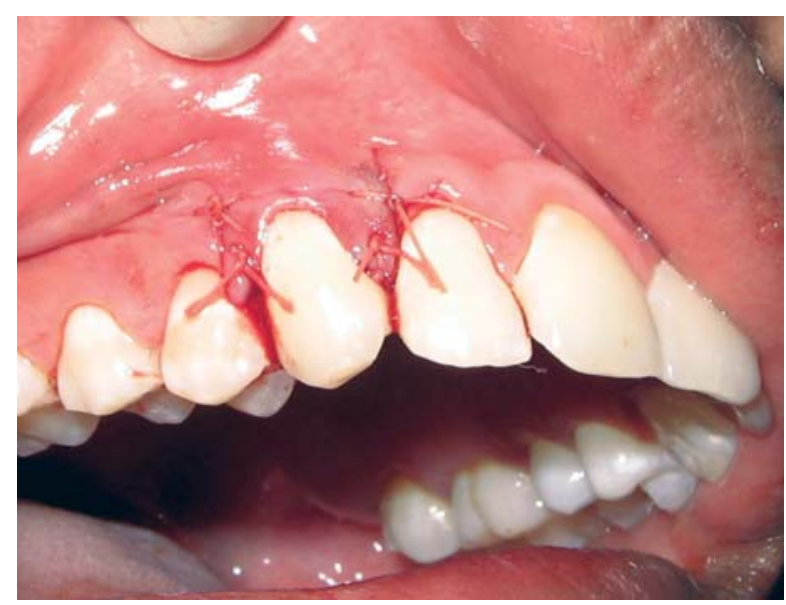

Fig. 4: Flap coronally anchored and sutured

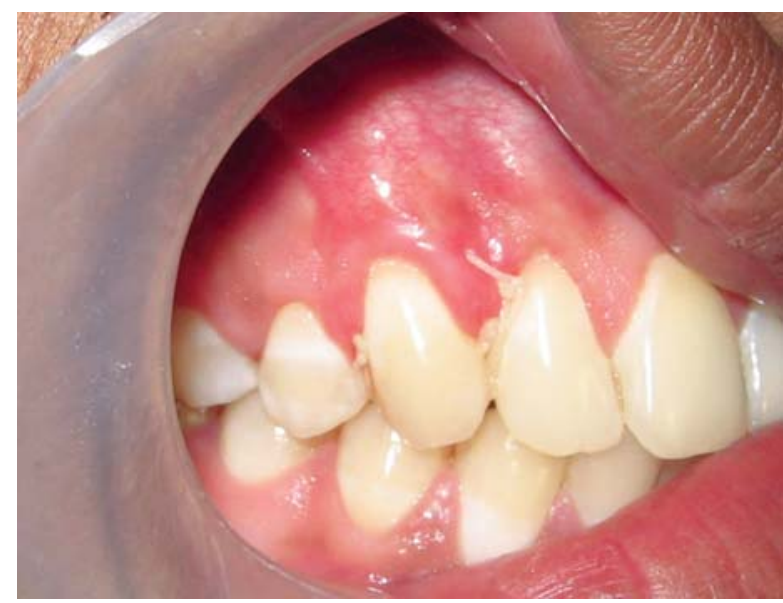

Fig. 5: One week postoperative view

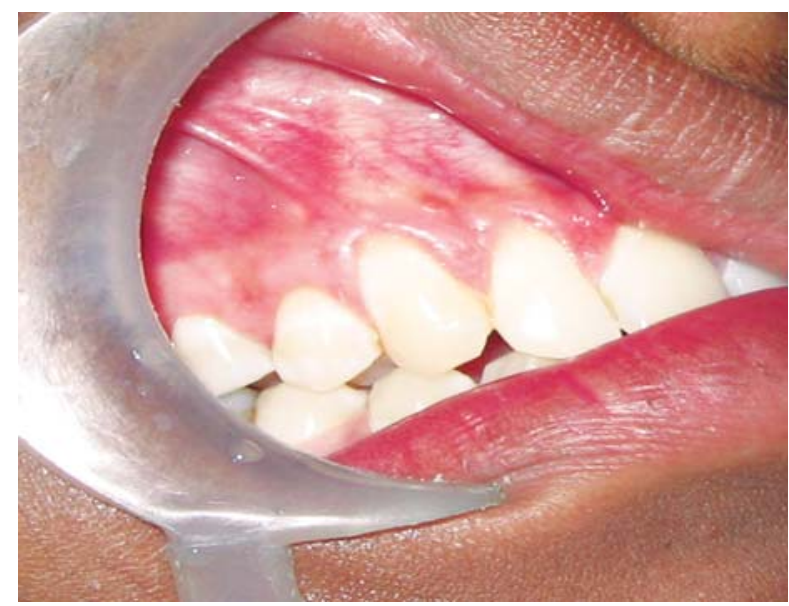

Fig. 6: Three months postoperative view

at the surgical site for at least four weeks. The patients were recalled weekly for the first month, and then at 3 and 6 months (Figs 5 to 7).

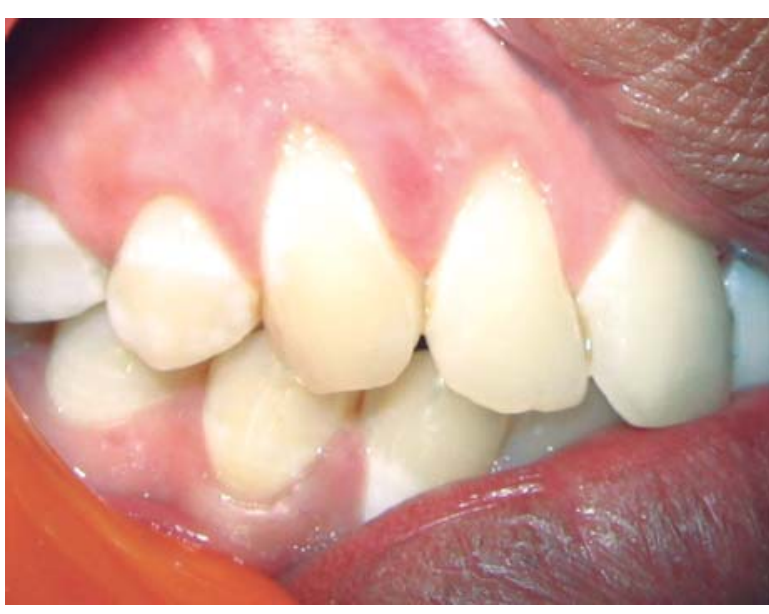

Fig. 7: Six months postoperative view

\section{Statistical Methods}

Chi-square and Fisher exact test were used to test the significance of homogeneity of sex distribution between membrane and CAF group. The student t-test/Mann Whitney $\mathrm{U}$ test was used to find the significance of study parameters between membrane and CAF group.

Repeated measures ANOVA was used to find the significance of study parameters from baseline through 3 and 6 months.

\section{RESULTS}

All the patients received the surgery well and there were no complications, such as infection, bleeding, swelling or excessive pain. None of the patients presented with any sign of rejection of the membrane, exposure of the membrane, allergic reactions or any other untoward events. Healing was uneventful in all the sites treated.

The study group comprised of seven male and three female patients with the mean age being 34.7 years (range 21-55).

The mean plaque scores at baseline 3 and 6 months were maintained at $0.78 \pm 0.22,0.90 \pm 0.29$ and $0.95 \pm 0.19$ respectively for the membrane group and $0.78 \pm 0.22,0.90 \pm$ 0.29 and $0.83 \pm 0.33$ respectively for the CAF group respectively. The mean gingival index scores at baseline 3 and 6 months were $0.83 \pm 0.35,0.90 \pm 0.47$ and $0.97 \pm 0.29$ respectively for the membrane group and $0.83 \pm 0.35$, $0.90 \pm 0.47$ and $0.93 \pm 0.33$ respectively for the CAF group. There was no statistically significant difference comparatively in the two groups with either of these parameters.

\section{Probing Depth}

The mean probing depth in the membrane group was $1.60 \pm$ $0.69 \mathrm{~mm}$ at baseline, which measured $1.70 \pm 0.67 \mathrm{~mm}$ at the end of the study. Similarly, the mean probing depth that measured $1.60 \pm 0.84 \mathrm{~mm}$ in the CAF group at baseline became $1.50 \pm 0.53 \mathrm{~mm}$ at the end of 6 months. Neither of these variations were statistically significant. There was no significant difference in probing depths between the two groups either at baseline or at the end of the study period. 


\section{Clinical Attachment Level}

The clinical attachment level (CAL) in the membrane group, which showed a mean of $4.20 \pm 1.14 \mathrm{~mm}$ at baseline became $2.20 \pm 0.78 \mathrm{~mm}$ at the end of the study period, showing a mean gain of $2 \mathrm{~mm}$ and amounting to an improvement of $47.6 \%$ (Graph 1). In the CAF group, the mean CAL gain, which was $4.50 \pm 0.71 \mathrm{~mm}$ at baseline improved to a mean of $2.80 \pm$ $0.79 \mathrm{~mm}$ by the end of the study. This amounted to a mean gain of $37.8 \%$. Both of these variations were statistically highly significant $(p=0.001)$. However, when the two groups were compared for the gain in CAL, the differences were not statistically significant.

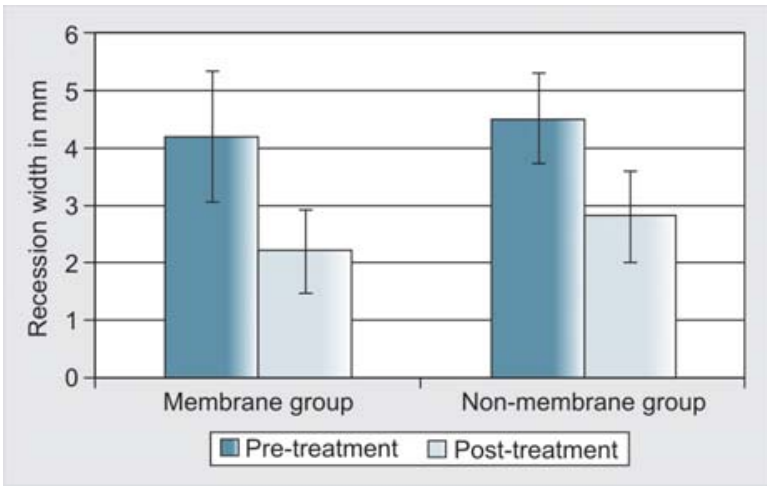

Graph 1: Clinical attachment level at baseline and 6 months

\section{Width of Keratinized Gingiva}

The mean width of keratinized gingiva in the membrane treated group at baseline, which was $3.30 \pm 1.06 \mathrm{~mm}$, increased to $4.90 \pm 0.88 \mathrm{~mm}$ at the end of 3 months and this increased width was maintained throughout the study. This amounted to $48.48 \%$, which was statistically highly significant. While in the CAF group, the width of keratinized gingiva was $3.20 \pm 0.79 \mathrm{~mm}$ at baseline, which marginally increased to a mean of $3.50 \pm 0.75$ $\mathrm{mm}$ at the end of the study. This slight increase $(9.37 \%)$ was not considered to be statistically significant (Graph 2).

A statistically highly significant increase in the width of keratinized gingiva was seen in the membrane group when compared to the CAF group.

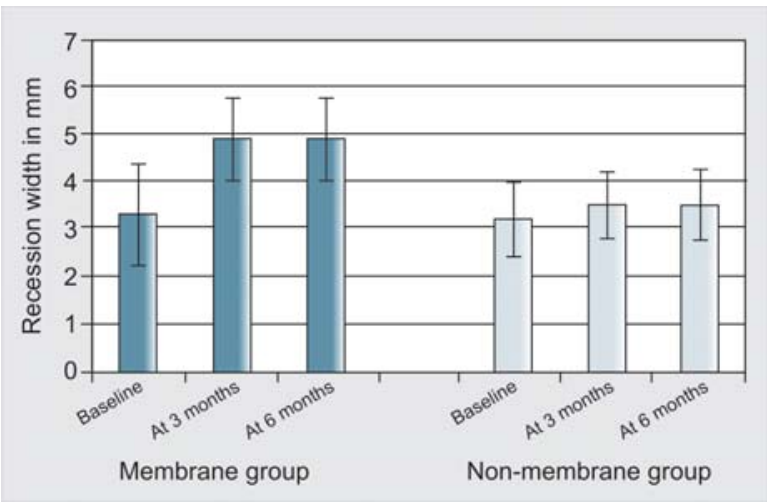

Graph 2: Width of keratinized tissue (WKT) at baseline, 3 months and 6 months in both the groups

\section{Recession Width}

The mean recession width in the membrane group was $3.60 \pm$ $0.69 \mathrm{~mm}$ at baseline, which decreased to $2.65 \pm 1.49 \mathrm{~mm}$ at 3 months and $2.45 \pm 1.42 \mathrm{~mm}$ at 6 months postoperatively. The change was statistically significant $(\mathrm{p}=0.026)$ with the improvement in width being $31.9 \%$. In the CAF group, the mean width of the recession at baseline was $3.70 \pm 0.67 \mathrm{~mm}$. This value decreased to $2.85 \pm 1.00 \mathrm{~mm}$ and $2.45 \pm 1.07 \mathrm{~mm}$ at 3 and 6 months postoperative respectively. The p-value was 0.016 , which was significant. A change of $33.8 \%$ in recession width was noted at the 6-month examination (Graph 3).

No difference was noted in reduction of recession width when the membrane and CAF groups were compared.

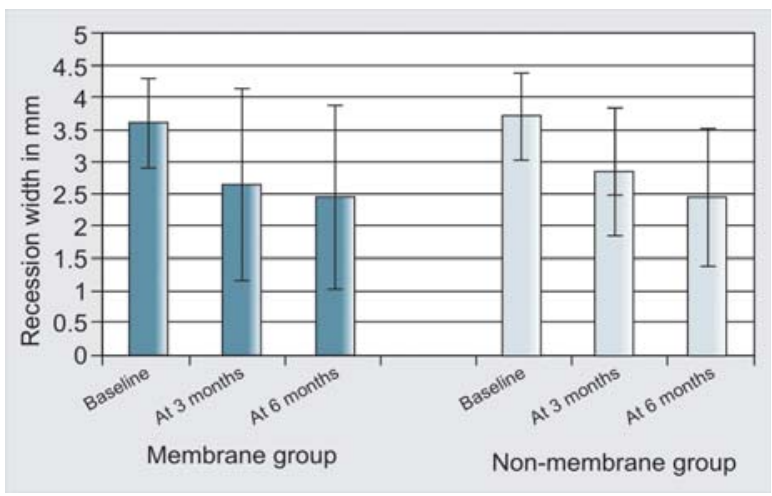

Graph 3: Recession width in both groups at baseline, 3 and 6 months

\section{Recession Depth}

The mean recession depth in the membrane group was $3.00 \pm$ $0.82 \mathrm{~mm}$ at baseline, which decreased to $1.05 \pm 0.59 \mathrm{~mm}$ at 3 and 6 months postoperatively. The change was statistically significant $(p=0.001)$ with the reduction in depth being $65 \%$. In the CAF group, the mean depth of the recession at baseline was $3.00 \pm 0.47 \mathrm{~mm}$. This value decreased to $1.35 \pm 0.75 \mathrm{~mm}$ at 3 and 6 months postoperatively. The p-value was $<0.001$, which was highly significant. A change of $55 \%$ in recession depth was noted at the 6-month examination (Graph 4).

As with recession width, no difference was noted in the reduction of the mean recession depth when the membrane and CAF groups were compared.

\section{Surface Area}

The membrane group showed a baseline surface area of $9.55 \pm$ $1.80 \mathrm{~mm}^{2}$, which decreased to $3.50 \pm 2.71 \mathrm{~mm}^{2}$ at 3 months and to $3.20 \pm 2.43 \mathrm{~mm}^{2}$ at 6 months postoperatively. The change was statistically significant ( $\mathrm{p}<0.001)$ and amounted to an increase of $66.49 \%$. The CAF group showed a surface area of $10.60 \pm 1.48 \mathrm{~mm}^{2}$ at baseline which decreased to $4.20 \pm$ $2.06 \mathrm{~mm}^{2}$ at 3 months and to $3.65 \pm 2.28 \mathrm{~mm}^{2}$ at 6 months postoperatively. This change was statistically significant amounting to an improvement of 65.56\% (Graph 5).

As with recession width and depth, no difference was observed when the membrane group was compared to the CAF group at 3 months $(p=0.523)$ and at 6 months $(p=0.65)$. 
Clinical Evaluation of Type I Bovine Collagen in the Treatment of Localized Gingival Recession

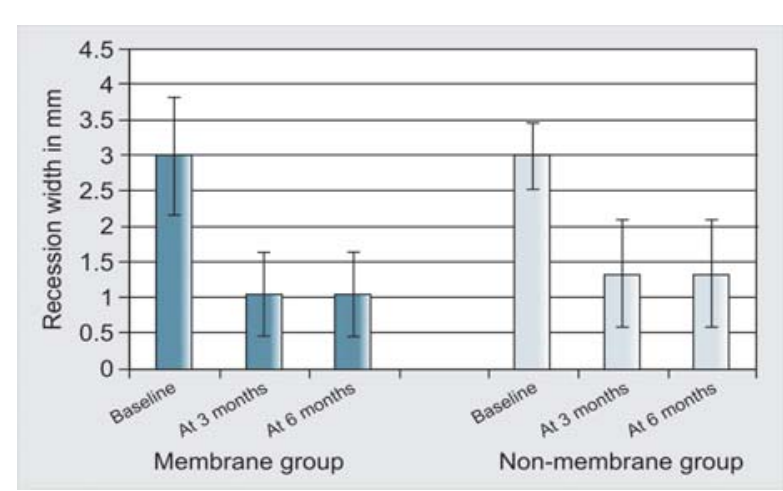

Graph 4: Recession depth at baseline, 3 months and 6 months

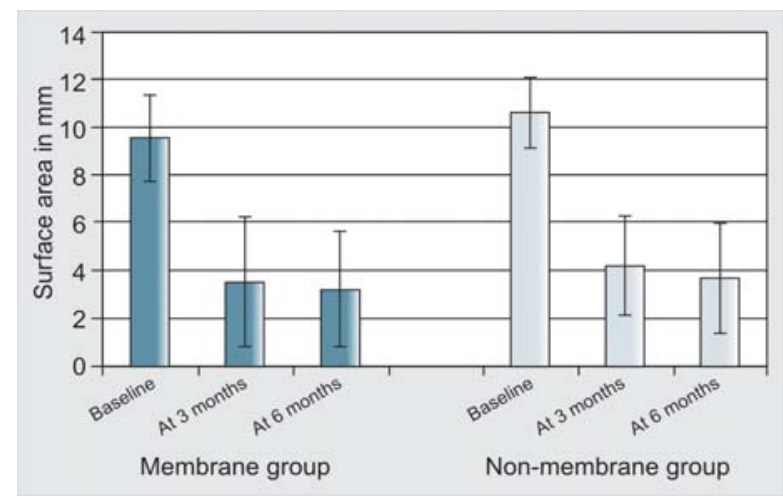

Graph 5: Surface area at baseline, 3 months and 6 months

\section{Percentage of Root Coverage}

Out of the 10 sites treated with membrane, one site showed complete root coverage. The mean percentage of root coverage seen in the membrane group at 3 months was $60.82 \pm 27.80 \%$, which marginally increased to $64.50 \pm 25.89 \%$ at 6 months postoperatively. In the CAF group, the mean percentage of root coverage was $61.00 \pm 22.34 \%$ at 3 months and $64.60 \pm 23.70 \%$ at 6 months postoperatively (Graph 6).

\section{DISCUSSION}

In the present controlled clinical trial, a randomized split mouth protocol was selected with the occurrence of similar defects on contralateral teeth. The patients were recalled at 1 week, 2 weeks, 1 month, 3 months and 6 months. At the one-week and two-week recall, careful supragingival scaling was done, taking care not to disturb the flap during healing. This was the routine protocol followed in all cases, as done in previous studies. ${ }^{11,24-27}$

The 3-month and 6-month data of the study showed that both treatments were equally effective. At 6 months, both treatments resulted in significant gain in root coverage by way of reduction in recession width, recession depth, surface area of the defect and gain in clinical attachment level (Figs 8 to 11). Plaque index, gingival index and probing depth showed no significant differences in either of the groups before and after treatment.

The clinical attachment level significantly increased in both the treatment groups at 6-month examination. No significant

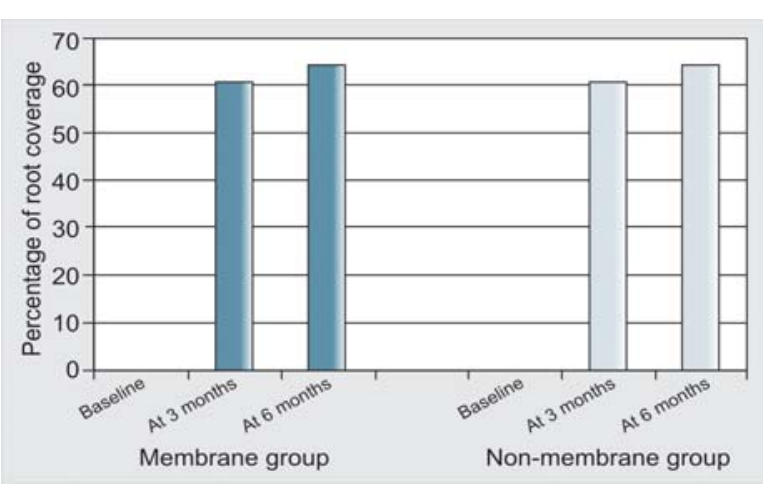

Graph 6: Percentage of root coverage

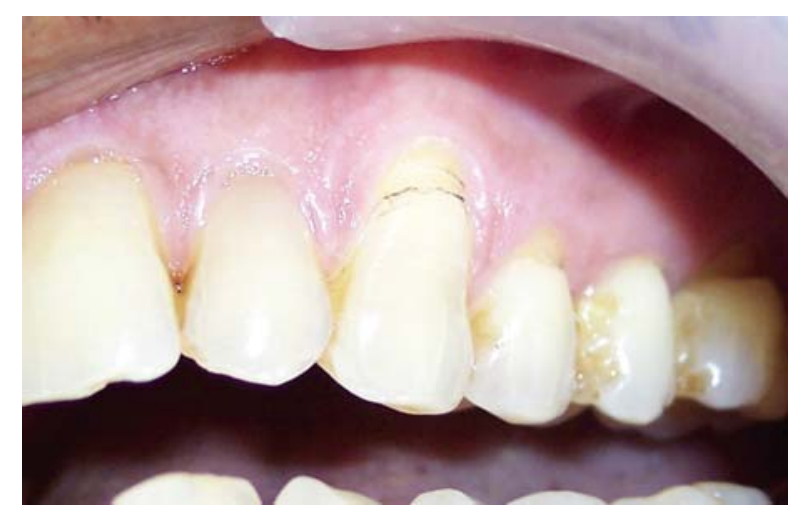

Fig. 8: Recession in relation to 23 prior to treatment

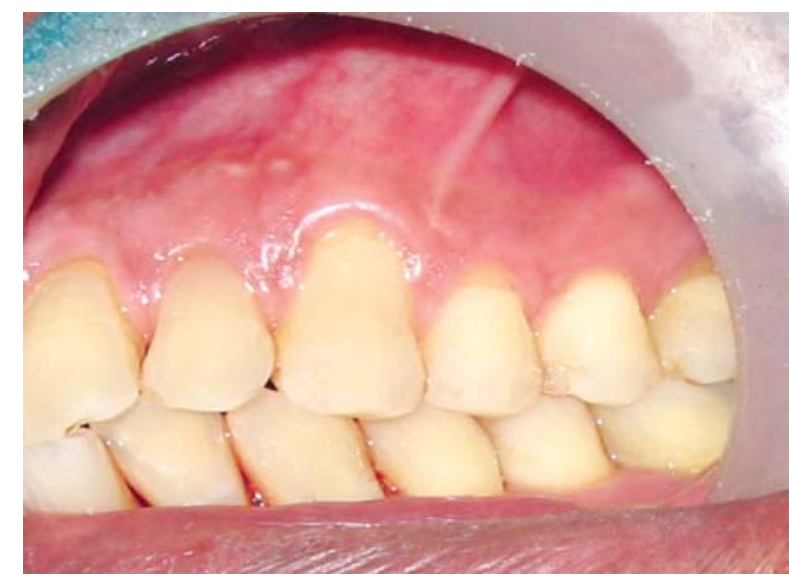

Fig. 9: The same tooth seen 6 months after treatment with CAF and membrane. Note the increase in the width of keratinized mucosa

differences were found when the attachment levels were compared between the groups, which agrees with other studies. ${ }^{16,28}$

The recession width and depth, and the surface area of the defect decreased in the membrane and CAF groups respectively. No significant differences were observed when the results of the treatment modalities were compared. While the results of the current study (66.49 and $65.56 \%$ in the membrane and CAF groups respectively) did not agree with some studies, ${ }^{30,31}$ they concurred with other studies. ${ }^{16,28}$ 


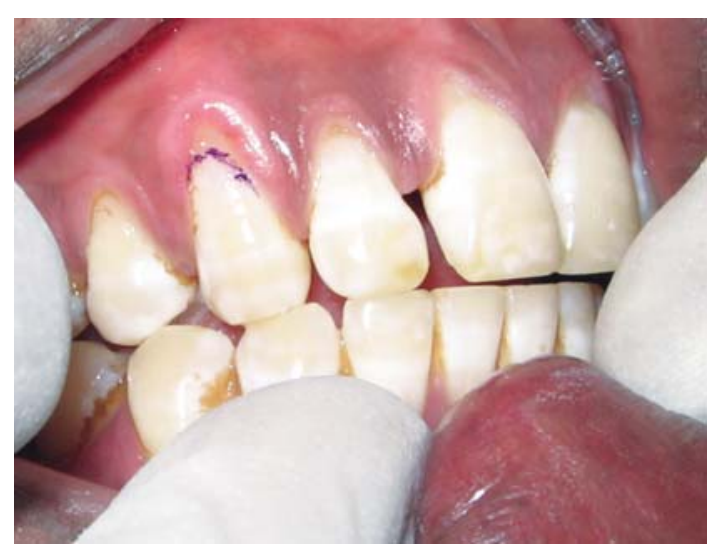

Fig. 10: Preoperative view of recession in relation to 13

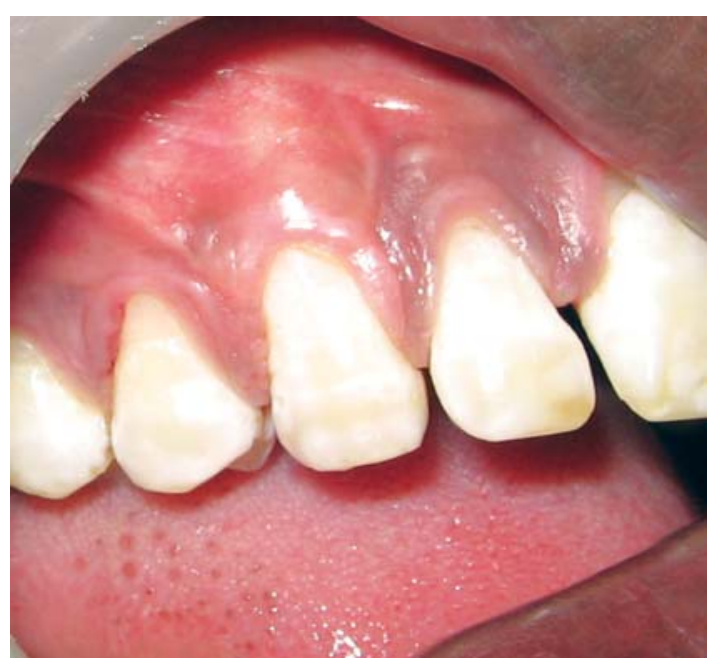

Fig. 11: Same tooth seen 6 months after being treated with $\mathrm{CAF}$ alone

The membrane group showed a mean increase in root coverage percentage of $60.82 \%$ at 3 months and $64.50 \%$ at 6 months respectively. The CAF group showed an increase of 61.00 and $64.60 \%$ at 3 months and 6 months respectively. These figures, while not in agreement with studies by Pini Prato et $\mathrm{al}^{28}$ and Zuchelli et $\mathrm{al}^{29}$ showing $80-100 \%$ root coverage, do agree with studies done by Trombelli et $\mathrm{al}^{30,31}$ and by Leknes et $\mathrm{al}^{16,27}$ which show mean root coverage of 55 to $65 \%$. Studies utilizing coronally advanced flap, show a mean defect coverage ranging from 50 to $98 \%$ with a mean for all studies being $78 \%$. Similarly studies utilizing bioabsorbable barriers show mean defect coverage ranging from 45 to $94 \%$ with a mean for all studies being $72 \%$. The results of the present study, albeit not up to generally expected levels, still do fall within results published by the AAP in 2005. ${ }^{32}$

Among all the parameters measured, the only significant difference between the treatment groups was seen when the width of keratinized gingiva was compared. An increase in the width of keratinized gingiva has been reported following GTR procedures in other studies as well. ${ }^{16,17,28}$ However, other studies showed only a modest gain in the width of keratinized gingiva when similar defects were treated with membranes. ${ }^{30,31}$

The 6-month data indicated that both treatments resulted in similar and significant gain in root coverage, amounting to $66.49 \%$ in the membrane group and $65.56 \%$ in the CAF group. Root coverage of up to $73 \%$ was reported with nonresorbable membranes in similar buccal recession defects in other studies. $^{28,29}$

One variable that was difficult to control was flap thickness. Pini Prato et al found that flap thickness $>0.8 \mathrm{~mm}$ was associated with complete root coverage while flaps thinner than this were associated with only partial root coverage. ${ }^{26}$ Some of the cases had thin gingiva and this could have been a significant predictor in determining the root coverage.

Unlike most studies, which measure root coverage by linear measurements, ${ }^{16,28-31}$ the current study attempted to measure root coverage more volumetrically by calculating the surface area.

Histological analysis of the type of attachment formed from the two treatments instituted was beyond the scope of this study. One would suspect, based on other studies, that the type of attachment obtained from guided tissue regeneration is a new connective tissue attachment, while that obtained from coronally advanced flap is a long junctional epithelium. ${ }^{33}$

\section{CONCLUSION}

The results of the current study show that coronally advanced flap procedures offer a simple and reliable treatment alternative as root coverage procedures in class I recession type defects. Combining this technique with the placement of a collagen membrane does not seem to improve the results in terms of root coverage. However, in sites where membrane was placed there was significant augmentation of keratinized gingiva. Both treatment procedures are highly technique sensitive, and their success depends upon a number of factors, which include the presence or absence of root prominences, thickness of the gingiva, level of interdental papilla, flap being sutured without tension and most importantly proper patient compliance. It is only when all these factors are fulfilled that these techniques become predictable.

\section{REFERENCES}

1. Albandar JM, Kingman A. Gingival recession, gingival bleeding, and dental calculus in adults over 30 years. J Periodontol 1999;70:30.

2. Watson PJ. Gingival recession. J Dent Res 1984;12:29.

3. Wennstrom JL. Some periodontal tissue reactions to orthodontic tooth movement in monkeys. J Clin Periodontol 1987;14:121.

4. Baker DL, Seymour GJ. The possible pathogenesis of gingival recession. J Clin Periodontol 1976;3:208.

5. Ozkavaf A, Berberoglu A. An unusual case of gingival recession. J Periodontol 2000;71:1767. 
6. Loe H, Anerud, Boysen. The natural history of periodontal disease in man. J Periodontol 1978;49:607.

7. Trott JR, Love B. An analysis of localized gingival recession in 766 Winnipeg High School students. Dent Pract Dent Res 1966;16:209.

8. Miller PD (Jr). Regenerative and reconstructive periodontal plastic surgery. Dent Clin North Am 1988;32:287.

9. Grupe J, Warren. Repair of gingival defects by a sliding flap operation. J Periodontol 1956;27:290.

10. Tarnow DP. Semilunar coronally repositioned flap. J Clin Periodontol 1986;13:182.

11. Allen EP, Miller PD (Jr). Coronal positioning of existing gingiva. J Periodontol 1989;60:316.

12. Bjorn H. Free transplantation of gingiva propria. Swedish Dent J 1963;22:684.

13. Langer B, Langer L. Sub epithelial connective tissue graft technique for root coverage. J Periodontol 1985;56:715.

14. Gottlow J, Karring T, Nyman S. Guided tissue regeneration following treatment of recession-type defects in the Monkey. J Periodontol 1990;61:680.

15. Tinti C, Vincenzi G, Coccheto R. Guided tissue regeneration in mucogingival surgery. J Periodntol 1993;64:1184.

16. Amarante ES, Leknes KN, Skavland J. Coronally positioned flap procedure with or without a bioabsorbable membrane in the treatment of human gingival recession. J Periodontol 2000;71:989.

17. Sheih AT, Wang HL, O’Neal R. Development and clinical evaluation of root coverage procedure using collagen barrier membrane. J Periodontol 1997;68:770.

18. Nemcovsky CE, Artzi Z, Tal H. A multicenter comparative study of two root coverage procedures: Coronally advanced flap with addition of enamel matrix proteins and sub pedicle connective tissue graft. J Periodontol 2004;75:600.

19. Harris RJ. A comparative study of root coverage obtained using acellular dermal matrix versus connective tissue graft. Int $\mathrm{J}$ Periodontics Restorative Dent 2000;20:51.

20. Pini Prato, Cortellini P, Clauser C. Guided tissue regeneration versus mucogingival surgery in the treatment of human buccal recessions. J Periodontol 1996;67:1216.

21. Wang HL, O'Neal R, Thomas L. Evaluation of an absorbable collagen membrane in treating class II furcation defects. J Periodontol 1994;65:1029.
22. Silness J, Loe H. Periodontal disease in pregnancy: Correlation between oral hygiene and periodontal condition. Acta Odontol Scand 1964;22:121.

23. Loe H, Silness J. Periodontal disease in pregnancy: Prevalence and severity. Acta Odontol Scand 1963;21:533.

24. Pini Prato G, Cortellini P. Coronally advanced flap: The postsurgical position of gingival margin is an important factor for achieving complete root coverage. J Periodontol 2005;76:213.

25. Pini Prato G, Cortellini P. Coronally advanced flap procedure for root coverage. Flap with tension versus flap without tension. J Periodontol 2000;71:188.

26. Pini Prato G, Cortellini P. Coronally advanced flap procedure for root coverage. Is flap thickness a relevant prediction to achieve root coverage? J Periodontol 1999;70:1077.

27. Leknes KN, Amarante ES, Price DE, Skavland RL. Coronally positioned flap procedures with or without a biodegradable membrane in the treatment of human gingival recession. A 6year follow-up study. J Clin Periodontol 2005;32:518.

28. Pini Prato G, Tinti, Vincenzi G, Cortellini P. Guided tissue regeneration versus mucogingival surgery in the treatment of human buccal recession. J Periodontol 1992;63:919.

29. Zuchelli G, Clauser C, DeSanctis M. Mucogingival versus guided tissue regeneration procedures in the treatment of deep recession type defects. J Periodontol 1998;64:138.

30. Trombelli L. Effects of tetracycline $\mathrm{HCl}$ conditioning and fibrinfibronectin system in the treatment of buccal gingival recession with GTR. J Periodontol 1995;66:313.

31. Trombelli L, Scabbia A, Wikesjo UME. Fibrin glue application in conjunction with tetracycline root conditioning and coronally positioned flap procedure. J Clin Periodontol 1996;23:861.

32. Informational Paper. Oral Reconstructive and Corrective Considerations in Periodontal therapy. J Periodontol 2005;76:1588.

33. Cortellini P, Clauser C, Pini Prato G. Histologic assessment of new attachment following the treatment of a human buccal recession by means of a GTR procedure. J Periodontol 1993;64:387. 